\title{
Kronik Hastaların Uzaktan İzlemine Yönelik Teletıp Platformu
}

\section{Telemedicine Platform for Remote Monitoring of Chronic Patients}

\section{H. Cumhur Tekin ${ }^{1 *}$}

1 İzmir Yüksek Teknoloji Enstitüsü, Biyomühendislik Bölümü, İzmir, TÜRKIYE

Sorumlu Yazar / Corresponding Author*: cumhurtekin@iyte.edu.tr

Geliş Tarihi / Received: 23.01.2019 Araștırma Makalesi/Research Article

Kabul Tarihi / Accepted: 05.08.2019 DOI: 10.21205/deufmd.2020226405

Atıf sekli/How to cite TEKiN, H.C. (2020). Kronik Hastalıkların Uzaktan İzlenmesine Yönelik Teletıp Platformu. DEUFMD 22(64),37-46.

Öz

Kronik hasta sayısı dünya genelinde artış göstermektedir. Bu nedenle kronik hastalıkların kontrol altına alınabilmelerinde etkili bir hastalık yönetimi ihtiyacı doğmuștur. Bu hastalıkların kontrolünde hastaların uzaktan takibine olanak sağlayan teletıp sistemlerinin büyük fayda sağlama potansiyelleri vardır. Etkin teletıp sistemlerinin geliştirilmesinde ise söz konusu bu sistemlerin ölçeklenebilirliğini ve sürdürebilirliğini sağlamak önem arz etmektedir. Bu çalışmada, kronik hastaların uzaktan izlemini gerçekleştirebilmek için yeni bir teletıp platformu önerilmektedir. Bu platform hastalara, sağlık verilerini sistem üstünden takiplerini yapan sağlık personeli ile doğrudan ve kolaylıkla paylașabilme olanağı sunmaktadır. Sağlık personeli ise, hastalık seyrindeki gelişmeleri ve tedavi hedeflerini bu veriler sayesinde uzaktan kontrol edebilmektedir. Ayrıca sağlık personeli, platform üstünden hastaya özel olarak belirleyeceği sağlık verisi eşik değerleri ile, kendisine ve/veya hastaya otomatik bildirim mesajı gönderebilmekte, böylelikle hasta verilerini sürekli manuel olarak incelemek yerine, platform üstünden gelecek bildirimler vasıtasıyla hastaya gerekli müdahaleyi vakit kaybetmeksizin yapabilmektedir. Önerilen platform ile kronik hastalık yönetimi iyileştirilebileceği gibi, sağlık personeline olabildiğince az iş yükü getirilerek verilecek sağlık hizmetinde verim ve kalite artışı sağlanabilecek, böylelikle platformun sürdürülebilirliği de temin edilebilecektir. Çalışmada platformun ölçeklenebilirliği, eş zamanlı istek testleri ile analiz edilmiştir. Platform üstünden bildirim mesajı göndermenin, 500 eş zamanlı istek için düşük tepki süresi (<750 ms), yüksek verimlilik (>200 istek/s) ve düşük hata oranı $(<\% 1.5)$ ile gerçekleştiği gözlenmiștir. Bu sonuçlar tasarlanan teletıp platformunun, birçok kullanıcıdan gelen veri akışının üstesinden gelebileceğini ve platformun ölçeklenebilir olduğunu göstermektedir.

Anahtar Kelimeler: Teletıp, Uzaktan Hastalık İzlem, Hastalık Yönetimi, Kronik Hastalıklar

\section{Abstract}

The number of patients with chronic diseases is increasing globally. Hence, an effective disease management to control chronic diseases is required. Telemedicine systems allowing remote monitoring of patients have a potential to bring great benefit for controlling these diseases. Developing effective telemedicine systems depends on ensuring the scalability and sustainability of 
DEU FMD 22(64), 37-46, 2020

these systems. Here, a new telemedicine platform is presented for remote monitoring of chronic patients. This platform provides patients to share their health data directly and easily with the healthcare personnel, who can remotely control disease progress and treatment goals with the shared data. Furthermore, the personnel can send an automatic notification message to themselves or/and to the patient when a patient specific health data threshold value set through the platform is reached. Hence, the healthcare personnel can improve the disease management with timely interventions using the platform notifications, instead of analyzing the data constantly. With this platform, chronic disease management can be enhanced and the sustainability of the platform can be ensured by bringing as little workload as possible to the personnel while increasing the efficiency and quality of health service. In the study, the scalability of the platform was analyzed using concurrent request tests. It was observed that sending the notification message through the platform was handled with low response time $(<750 \mathrm{~ms})$, high throughput $(>200$ requests $/ \mathrm{s})$ and low error rate $(<1.5 \%)$ for 500 concurrent requests. These results show that the designed telemedicine platform can manage the data flow from many users and the platform can be scalable.

Keywords: Telemedicine, Remote Disease Monitoring, Disease Management, Chronic Diseases

\section{Giriş}

Kalp hastalıkları, diyabet, kanser ve kronik akciğer hastalıkları gibi bulașıcı olmayan hastalıklar uzun süreli tedavi gerektirmektedir [1]. Bu hastalıklar aynı zamanda kronik hastalıklar olarak da bilinir. Kronik hastalıklar 2016 yılında 56.9 milyon küresel ölümün \% 71'ine sebep olmuș olup [2], hastane kabullerinin de \% 30-85'ini oluşturmaktadırlar [3-5]. Ayrıca, kronik hastalıklar sağlık harcamalarından en büyük payı almakta olup, bu hastalıklardan kaynaklanan toplam ekonomik kaybın 2030 yılında küresel çapta 47 trilyon ABD dolarına ulaşacağ Sağlıksız yaşam tarzı ve yaşlanan nüfus nedeniyle, kronik hasta sayısı artmaktadır [7]. Bununla birlikte, kronik hastalıklar, davranış risk faktörleri (sigara kullanımı, alkol kullanımı, fiziksel hareketsizlik, sağlıksız beslenme) ve metabolik risk faktörleri (yüksek tansiyon, obezite, hiperglisemi, hiperlipidemi) kontrol altına alınarak azaltılabilirler [8]. Kronik hastalık yönetimi için hastalar, tansiyon aleti ve kan şekeri ölçüm cihazları gibi el tipi medikal cihazlar ile sağlık durumlarını ev ortamında izleyebilmektedirler. Hastalar bu ölçüm değerlerini ancak periyodik muayeneleri sırasında doktorları ile yüzeysel olarak paylaşabilmektedirler. $\mathrm{Bu}$ sebeple doktorlar ölçüm değerlerine anında erișememekte ve ölçüm değerlerindeki düzensizlikleri gerektiği şekilde gözlemleyememektedirler. $\mathrm{Bu}$ da hastalık yönetimi kalitesini azaltmaktadır [9, 10].
Teletıp kelime anlamıyla "uzaktan iyileșme" anlamına gelmekte olup, hastalıkların uzaktan teşhisi, takibi ve tedavisinin yapılmasını sağlamakta ve sağlıkta coğrafi engelleri ortadan kaldırmaktadır [11]. Teletıp araçlarıyla, hastalar çevrimiçi tıbbi konsültasyon alabilmekte ve sağlık verilerini depolayıp sağlık personellerine aktarabilmektedirler [12]. Bunun dışında, teletıp sistemlerine entegre edilen hasta başı veya giyilebilir sensörlerle hasta verileri sağlık personeline otomatik olarak aktarılıp hastaların gerçek zamanlı uzaktan takibi yapılabilmektedir [13-15]. Teletıp servisleri hastaların uzaktan izlenmesine, hastalık yönetimini iyileștirmeye ve kişiye özel hasta bakımı sunmaya elverișli olduğundan kronik hastalar bu servislerden büyük yarar görebilirler [16, 17]. Bu servislerle hastalar, sağlı hizmeti sağlayıcılarından zamanında uzaktan geri bildirim alabilirler. $\mathrm{Bu}$ nedenle söz konusu servisler ilk basamak sağlık hizmetlerine doğrudan erișimi olmayan kırsal ve yarı kırsal bölgelerde yaşayan hastalar için oldukça faydalıdır [18]. Bununla beraber, teletıp servisleri ile ev ortamında hastanın tedavisine devam edilip uzun süreli, masraflı ve hasta açısından yıpratıcı hastane yatışlarının önüne geçilebileceği gibi, hastane kapasitesinin daha etkili kullanılması da sağlanabilir [19]. Evde yapılan tansiyon izlemi, sağlık personeli tarafından uzaktan ilaç dozajını ayarlamak için kullanıldığında tansiyon kontrolü daha iyi sağlanabilmektedir [20]. Örneğin, SMS yoluyla tansiyon ölçümlerini ileten ve uzaktan izlemi yapılan hastalar, kendi takiplerini kendileri yapan ve rutin klinik kontrolü yapılan hastalara göre en az iki kat (yani 6 ay kadar) daha hızlı 
DEU FMD 22(64), 37-46, 2020

sürede düșük tansiyon değerlerine ulașabilmișlerdir [21]. Ayrıca, tansiyon aleti kullanan hipertansiyon hastalarına otomatik telefon izleminin yapılması ile hasta sonuçlarının iyileștirildiği gösterilmiştir [22, 23]. Bir bașka çalıșmada, kronik kalp yetmezliği olan hastaların uzaktan takibi için hemșireler tarafından telefon ile izleme stratejisi sunulmuş ve hasta sonuçlarında iyileşme olduğu görülmüştür [24]. Sağlık verilerinin uzaktan web tabanlı ve mobil uygulamalar üzerinden yüklenmesi ve ardından bu veriler doğrultusunda sağlık personeli tarafından hastaya geri bildirimlerde bulunulması da kronik hastalık yönetimi üzerinde olumlu bir etkiye sahiptir $[17,25,26]$.

Sağlık personeli kronik hastalık tedavisi süresince, hasta sağlık verilerindeki düzensizlikleri tespit eder ve hedef sağlık verisi değerine tedavi ile ulaşılıp ulaşılmadığının kontrolünü sağlar, böylece en iyi tedaviyi sağlamak için hastaya özel bir hastalık yönetimi stratejisi uygulayabilir [27-29]. Teletıp sistemleri bu kontrollerin uzaktan yapılmasına imkan vermekte olup, hastaya zaman kaybetmeksizin müdahalede bulunulmasının önünü açmaktadırlar. Ancak, hasta sağlık verilerinin analizi, teletıp sistemlerinin sürdürülebilirliğini sağlamak amacıyla sağlık personelinin iş yükü minimum ölçüde artırılarak yapılmalı ve aynı zamanda çoklu kullanıcıya destek vermesi için ölçeklenebilir olmalıdır [30, 31].

$\mathrm{Bu}$ çalıșmada, hasta sağlık verilerini (tansiyon veya kan şekeri) depolayan ve kronik hastalık yönetimi için sağlık personeline aktaran yeni bir teletıp platformu sunulmaktadır. Sağlık personeli, sağlık verisindeki (sistolik, diyastolik, nabız ve kan şekeri seviyesi) düzensizlikleri tanımlamak için platformda hastaya özel bildirim değerleri ayarlayabilmektedir. Bildirim değerlerine ulaşılması halinde, hastalar ve sağlık personeli platform tarafından otomatik bildirim mesajı ve/veya bildirim e-postası ile uyarılabilmekte, böylelikle hastaya anında müdahalenin yapılması sağlanabilmektedir. Platform ile doktorun hasta verilerini sürekli manuel olarak takip etmesi zorunluluğu ortadan kaldırılmakta, bu ise platformun sürdürülebilirliğini artırmaktadır. Platformun ölçeklenebilirliği ise farklı kullanıcı senaryoları için eş zamanlı isteklerde bulunularak test edilmiș ve platform performansı analiz edilmiștir.

\section{Gereç ve Yöntem}

\subsection{Teletıp platformu}

Tasarlanan teletıp platformu Şekil 1'de gösterilmiştir. $\mathrm{Bu}$ platformda hastalar webtabanlı uygulama üstünden tansiyon aleti kullanarak elde ettikleri sistolik/diastolik kan basıncı ve nabız değerlerini veya şeker ölçüm cihazı kullanarak elde ettikleri kan şekeri ile insülin dozu ve açlık durumu bilgilerini anlık olarak kaydedebilmektedirler. Bu değerleri yine uygulama üstünden gözlemleyebilmektedirler. Hastalar teletıp platformuna tanımlı sağlık personeli ile sağlık değerlerini paylaşabilmektedirler. Sağlık personeli ise bu hasta değerlerini uygulama üstünden gözlemleyebilmektedir. Sağlık personeli hasta verilerindeki düzensizlikleri anında belirleyebilmek amacıyla, uygulama üstünden hasta özelinde sağlık verilerinin ulașmaması istenen değerleri (bildirim değerleri) girip, bu değerlere ulașılması halinde kendine ve hastaya uygulama üstünden otomatik bildirim mesajı veya bildirim e-postası gönderilmesini sağlayabilmektedir. Şöyle ki; personel, uygulama üstünden her sağlık verisi için hastaya özel eşik değerini belirleyip, bu değerin üstünde veya altında bir değer olması halinde kendisine ve hastaya bildirim gönderilmesini talep edebilmektedir. Sağlık personeli hastaya özel olarak gönderilecek bildirim mesajının içeriğini de uygulama üstünden kendisi belirleyebilmektedir. Uygulama üstünden girilen sağlık verileri ve bildirim istemleri sunucuya gönderilerek veri tabanına kaydedilirler. Uygulamaya hasta tarafından girilen sağlık verileri sunucuda ișlenip sağlık personelinin belirlediği bildirim değerleri ile karșılaștırılırlar. Bir bildirim oluşması sonucunda uygulama üstünden hasta ve hastanın takibini yapan sağlık personeli bilgilendirilir.

Hastalar sağlı verilerini JSON formatında PHP isteği ile sunucuya göndermektedirler (Şekil 2). Gönderilen veride, 6 basamaklı kullanıcı numarası, 64 basamaklı kullanıcıya özel sunucu erişim anahtarı, sağlık verisi cinsi (tansiyon veya kan şekeri) ve sağlık verileri (sistolik kan basıncl, diastolik kan basıncı ve nabız veya kan şekeri, açlık durumu ve insülin dozu) bulunmaktadır. Kullanıcı numarasına (kn) özel erișim anahtarı ile sunucuya erişildikten sonra, gönderilen sağlık 
DEU FMD 22(64), 37-46, 2020

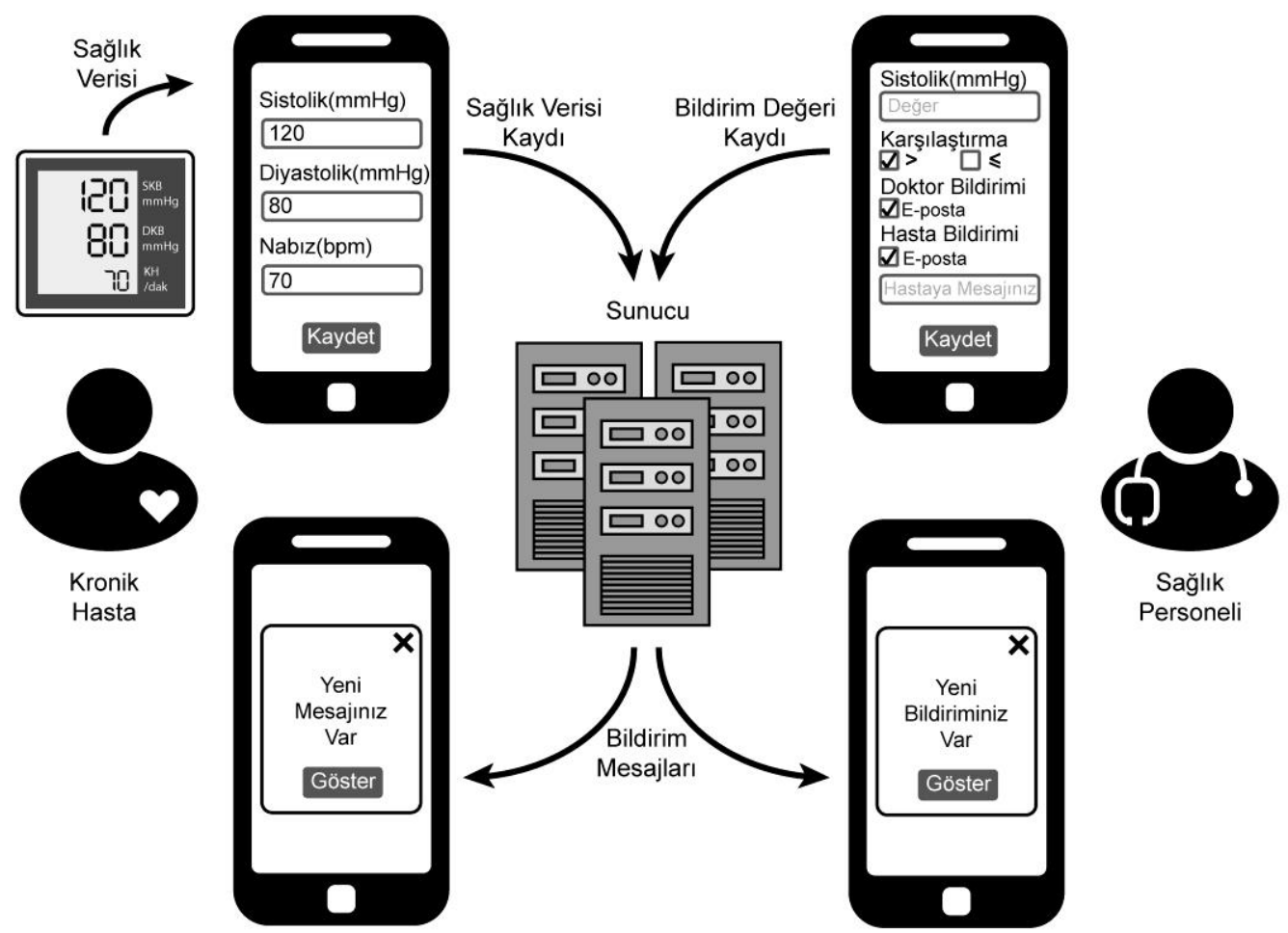

Şekil 1. Kronik hasta takibi için teletıp platformu

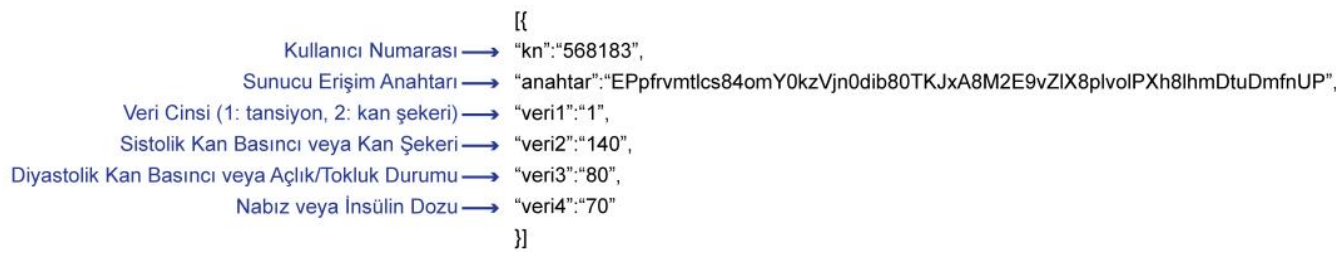

Şekil 2. JSON formatında gönderilen tansiyon verisi örneği

veri cinsine (veri1) özgü sağlı değerleri (veri2veri4) sunucuda işlenir. Kaydedilmek istenen veri eğer tansiyon değerini içeriyorsa veri1 1 olarak, kan şekeri değerini içeriyorsa veri1 2 olarak gönderilir. Tansiyon değeri gönderildiğinde veri2 sistolik kan basıncı ( $\mathrm{mmHg}$ ), veri3 diyastolik kan basıncı ( $\mathrm{mmHg}$ ) ve veri4 nabız (atım/dk) değerlerini içerir. Kan şekeri değeri gönderildiğinde ise veri2 kan șekeri (mg/dl), veri3 ölçüm sırasındaki açlık durumu (0: aç, 1: tok) ve veri4 ölçüm öncesindeki uygulanan insülin dozu (ünite) değerlerini içerir. Sunucu üzerinde veriler, veri güvenliğini sağlamak için 128-bit anahtar kullanılarak Gelişmiş Şifreleme Standardı (AES) ile şifrelenip saklanmaktadır. Gelen verideki bilgiler veri tabanındaki kullanıcı kimliği ve kullanıcı anahtarı ile eşlenirse gelen sağlık verileri veri tabanına kaydedilmektedir.

Sunucuya gönderilen sağlık verileri üzerinde uygulanan işlem şeması Şekil 3'de gösterilmiștir. Veri tabanında bildirim değeri bulunuyorsa veri ișlem akıșı devam eder, bulunmuyorsa akıștan çıkılır (Çıkış 1). Sağlık verisi bildirim değeri ile eşleșiyorsa hasta takibini yapan sağlık personeli için bildirim mesajı oluşturulup veri tabanına kaydedilir. Ĕger sağlı verisi bildirim değeri ile eşleşmiyorsa veri işlem akışından çıkılır (Çılkış 2). Bundan sonraki basamaklarda, hem e-posta hem de uygulama üstünden mesaj olarak veya sadece uygulama üstünden mesaj olarak iki 
DEU FMD 22(64), 37-46, 2020

farklı bildirim gönderme yöntemi kullanılmıștır. Eğer bildirim için e-posta gönderim yöntemi

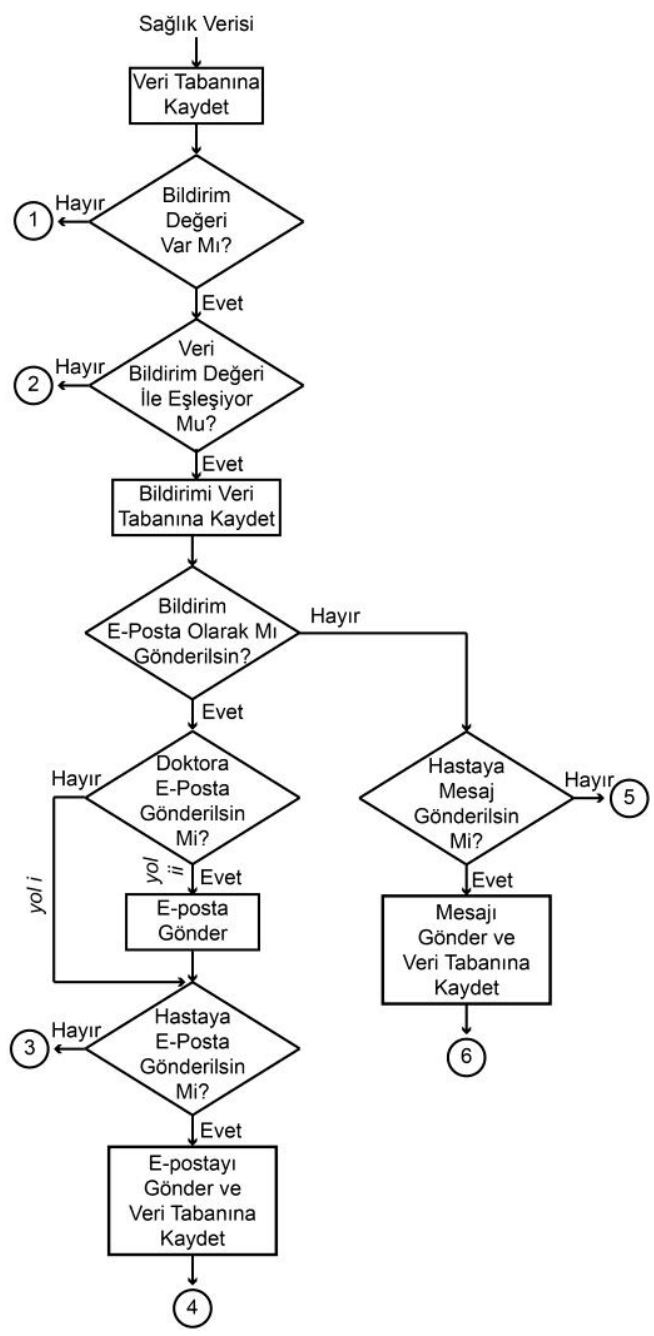

Şekil 3. Sunucu üstünde gerçekleşen veri işlem basamakları.

kullanılırsa, ilk önce sağllk personeline e-posta gönderme gerekliliği kontrol edilir (Yol i veya Yol ii) ve gönderim gerekliyse e-posta gönderilir (Yol ii). Daha sonra hastaya e-posta gönderme gerekliliği kontrol edilip, gönderme gerekli ise eposta gönderilip veri tabanına gönderilen eposta bildirim mesajı olarak kaydedilir ve veri işlem akışından çıkılır (Çııkıș 4). E-posta gönderimi gerekli değilse hemen akıştan çıkılır (Çıkış 3). Bu işlemler sırasında, hasta takibini yapan sağlık personelinin ve hastanın e-posta bilgileri ile hastaya özel bildirim mesajı veri tabanından elde edilir. Eğer bildirim için uygulama üstünden mesaj gönderme yöntemi kullanılırsa, hastaya mesaj gönderme gerekliliği kontrol edilip gerekliyse bildirim mesajı oluşturulup veri tabanına kaydedilerek veri işlem akışından çıkılır (Çıkış 6). Eğer gerekli değilse akıştan çıkılır (Çıkış 5). Veri tabanına kaydedilen mesajlar uygulama üstünden kullanıcılara bildirilir.

\subsection{Eş zamanlı istek testleri}

Teletıp platformunun performansı, eş zamanlı sağlık verisi gönderilerek test edilmiștir. Internet bağlantı hızının performansa olan etkisini önlemek adına testler yerel sunucuda yapılmıştır. Bunun için $2.7 \mathrm{GHz}$ Intel Core i5 işlemci ve 8 GB DDR3 RAM'e sahip MacBook Pro (Retina, 13-inch, Early 2015) dizüstü bilgisayar kullanılmıștır. XAMPP yazılımı (versiyon 5.6.8-0) ile bu bilgisayarda yerel sunucu olușturulmuș ve MySQL (versiyon 5.6.24) veri tabanı hazırlanmıştır. Uygulamanın eș zamanlı veri girişine gösterdiği performansı ölçmek için Apache JMeter yazılımı (versiyon 3.2) kullanılmıștır. $\mathrm{Bu}$ yazılımla farklı sayılardaki sanal kullanıcı $(100,200,300,400,500) 1$ saniye içinde JSON verisini PHP isteği ile yerel sunucuya göndermiş ve 2 saniyelik döngü boyunca istek kullanıcılar tarafından 2 kere tekrarlanmıștır. Sunucuya gönderilen JSON verisinin büyüklüğü $\sim 0.2$ kB'dır.

JMeter yazılımının verdiği tepki süresi (bir isteğin işlem süresi), verimlilik (saniye bașına işlenen istek sayısı) ve hata oranı (başarısız isteklerin gönderilen tüm istekler içindeki oranı) farklı eş zamanlı istek sayıları ve Şekil 3'de gösterilen farklı veri işlem akış senaryoları [Çıkış 1, Çıkış 2, Yol i üstünden Çıkış 3 (Çıkış 3i), Yol ii üstünden Çıkış 3 (Çılkış 3ii), Yol i üstünden Çıkış 4 (Çıkış 4i), Yol ii üstünden Çıkış 4 (Çıkış 4ii), Çıkış 5 ve Çılkış 6] için analiz edilmiştir. Veri ișlem akıșları sonucunda gönderilen örnek bildirimler Şekil 4'te verilmiştir. Bu örnekler için doktor sistolik kan basıncı değerinin 180 mmHg'den büyük olduğu durumda hastaya ve kendisine bildirim (e-posta veya uygulama üstünden mesaj) gönderilmesini seçmiștir. Hasta sistolik değerini 180 mmHg'den büyük bir değer olarak girdiği zaman doktorun hastaya gönderilmesini istediği mesaj veri tabanından alınmış, doktora da oluşan bildirim durumunu açıklayan mesaj otomatik olușturulmuş ve 


\section{DEU FMD 22(64), 37-46, 2020}

bildirim olarak gönderilmiștir. Bu mesajlar, Șekil 4'teki bildirimlerde sarı ile işaretlenmiştir. Bildirimlerdeki boşluk bırakılan kısımlar ise veri tabanından alınan ilgili hasta ve doktor isimleri ile hasta ve doktor kullanıcı numaralarını içerecektir. Bildirimi e-posta olarak göndermek için PHP'de e-posta oluşturma ve aktarma sınıfi olan PHPMailer (versiyon 5.2.8) kullanılmıștır.

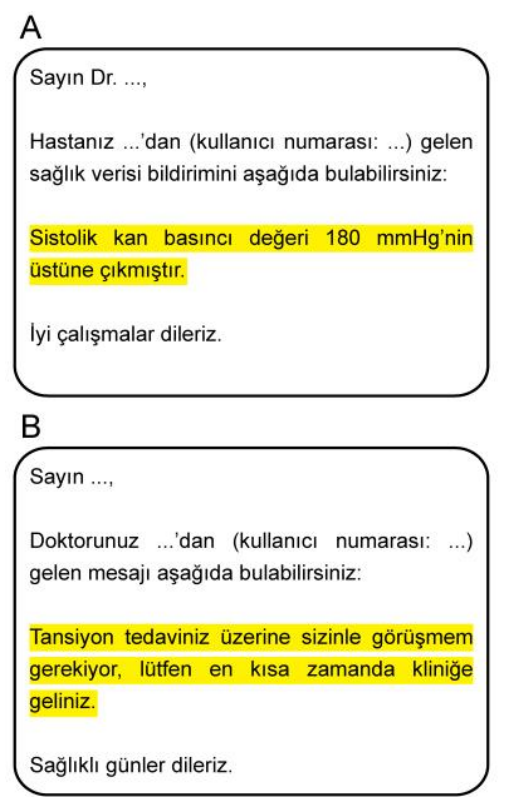

Şekil 4. Örnek bildirimler. A) Doktora ve B) hastaya iletilen bildirimler.

\section{3.İstatistiksel analizler}

Tepki süresi ile eş zamanlı istek arasındaki ilişkinin belirlenmesi için doğrusal regresyon modeli kullanılmıştır. Doğrusal regresyon modelinin belirleme katsayısı $\left(\mathrm{R}^{2}\right)$ hesaplanmıştır. Ayrıca, Çıkış 6 senaryosunda elde edilen veri grupları üzerinde bir yönlü ANOVA ve Tukey çoklu karşılaștırma testi yapılarak veri gruplarının istatistiksel olarak farklı olup olmadığı incelenmiştir. P değerinin 0.05 altında olduğu durumlarda anlaml farklılığın bulunduğu kabul edilmiștir.

\section{Bulgular}

Geliştirilen teletıp platformunun, veri işlem akıșındaki farklı senaryolar için eș zamanlı istek analiz sonuçları Şekil 5'te gösterilmiștir. Şekilde çeşitli eş zamanlı istek değerlerine göre ortaya çıkan tepki süresi, verimlilik ve hata oranları analiz edilmiştir.
Genel olarak eş zamanlı istek sayısı arttıkça tepki süresi doğrusal olarak artmaktadır. Şöyle ki; eş zamanlı istek için bildirimin yapılmadı̆̆ı veya bildirimin uygulama üstünden mesaj ile yapıldığı (Çıkış 1, Çıkış 2, Çıkış 3i, Çıkış 5 ve Çıkış 6) durumlarda $\mathrm{R}^{2}$ değeri 0.95 ve üstü olarak gözlemlenmiştir. Bildirimin e-posta ile yapıldığı durumlar olan Çıkış 3ii, Çıkıș 4i ve Çıkış 4ii için $\mathrm{R}^{2}$ değeri sırasıyla $0.90,0.77$ ve 0.57 olarak hesaplanmıştır. Ancak Çıkış 4ii için istatistiksel olarak anlamlı korelasyon gözlemlenmemiștir $(\mathrm{P}>0.05)$. Bu da Çıkış 4ii hariç diğer veri akış seneryolarında es zamanlı istekle tepki süresi arasındaki doğrusal ilişkiyi göstermektedir. Bildirimin e-posta ile yapıldığı durumlarda ortalama tepki süresi 100 eș zamanlı istek için en düşük Çıkış 3ii'de 1500 ms olarak ölçülürken, 500 eș zamanlı istek için en yüksek Çıkıș 4ii'de $\sim 6500$ ms olarak ölçülmüştür. E-posta gönderilmediği durumlar için ortalama tepki süresi 100 eş zamanlı istek için 35 ms'nin, 500 eş zamanlı istek için 750 ms'nin altında kalmıştır. Görüldüğü üzere e-posta ile bildirim gönderilmesi, tepki süresini, sadece mesaj ile bildirim göndermeye göre $\sim 40$ kata kadar artırmaktadır.

Bildirimin e-posta ile yapılmadığı durumlarda (Çıkış 1, Çıkış 2, Çıkıș 3i, Çıkış 5 ve Çıkıș 6) verimlilik genel olarak eş zamanlı istek miktarı ile artış gösterirken $\sim 250$ istek/s verimlilik değerine ulaşıldığında sabit kalmaktadır. Bildirimin e-posta ile yapıldığı durumlarda (Çıkış 3ii, Çılkıș 4i ve Çıkıș 4ii) ise eș zamanlı istek sayısı artsa da verimlilik 40 istek/s'nin üzerine çıkamamıştır. Bu sonuç e-posta ile bildirim gönderilmediği durumlarda yüksek verimliliğe ulaşılabileceğini göstermektedir.

Hata oranı tüm durumlar için eş zamanlı istek sayısı ile artmaktadır. 200 eş zamanlı istek için bildirimin e-posta ile yapılmadı $\breve{g}_{1}$ durumlarda tüm istekler kayıpsız iletilerek hatasız gönderim yapılabilmiştir. Bu durumlar için eş zamanlı istek sayısı artınca hata oranları az miktarda yükselse de, 500 eş zamanlı istek için hata oranları $\% 1.5$ 'in altında kalmıștır. Bildirimin e-posta ile gönderildiği durumlarda ise 100 eş zamanlı isteğe kadar hatasız gönderim yapılabilmiștir. Ancak eș zamanlı istek miktarı arttıkça hata oranları çok fazla artarak 500 eş zamanlı istek için \%30'a kadar çıkabilmektedir.

Bildirimin e-posta ile yapılmadığı durumlarda performans bakımından tepki süresi, verimlilik 
DEU FMD 22(64), 37-46, 2020

ve hata oranlarında benzerlik görülmüștür. Bu da gelen sağlık verisini sadece veri tabanına kaydetmekle (Çıkış 1), bu veriyi işleyip bildirim mesajı oluşturmanın (Çıkış 6) sistem performansı üzerinde etkisinin olmadı̆̆ını göstermektedir. Bildirimlerin hasta ve/veya doktora e-posta ile gönderildiği durumlarda
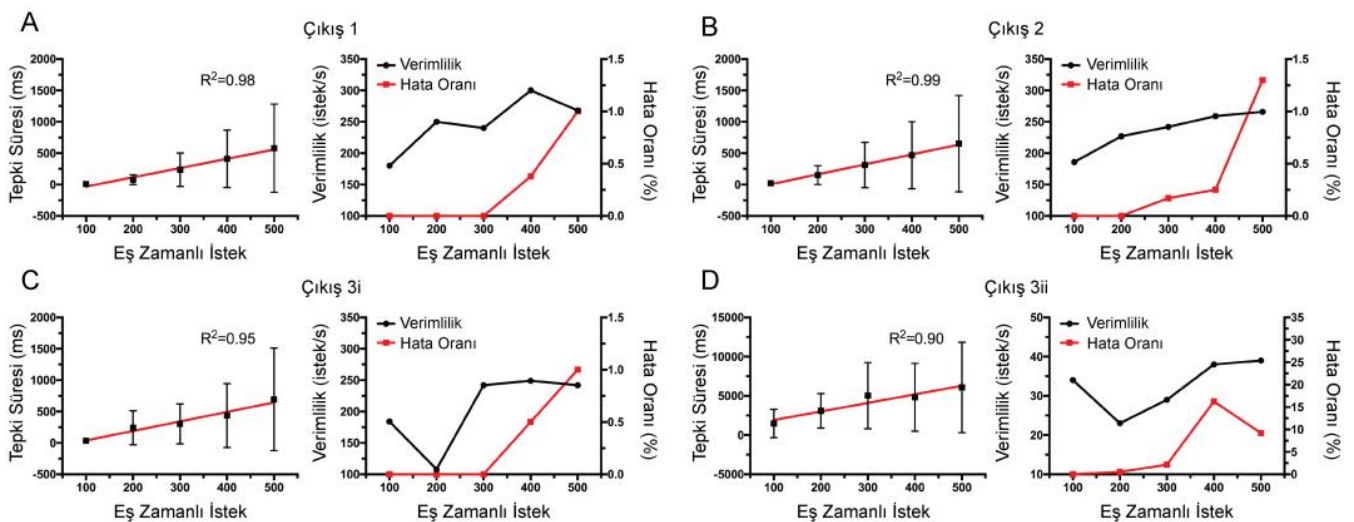

Çıkış $3 i$

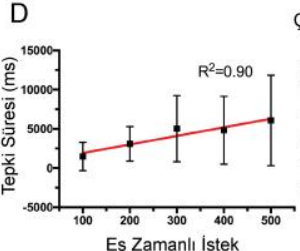

Çıkış 3ii
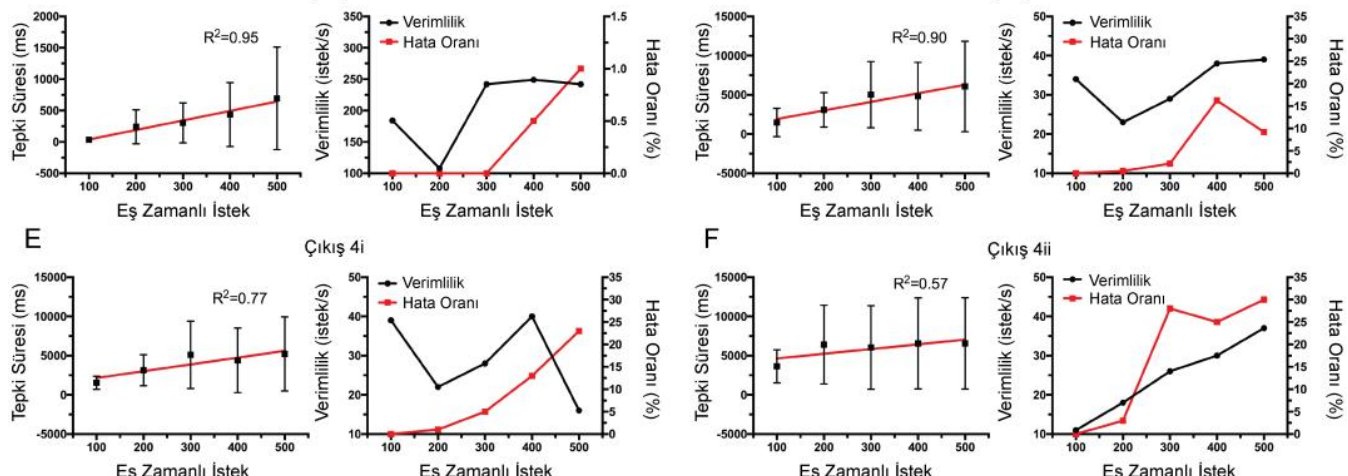

Çıkış 4 ii

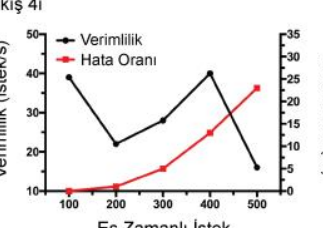

${ }^{50} \rightarrow-$ -

ș Zamanlı istek

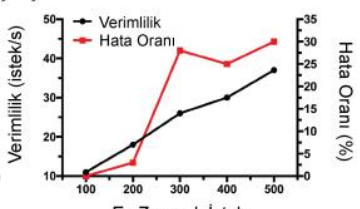

$\mathrm{H}$

$\begin{array}{ll}200 & 300 \\ \text { Es Zamanlı istek }\end{array}$

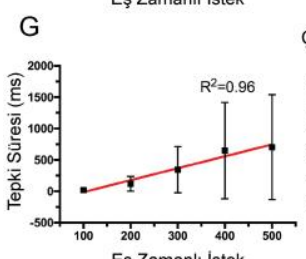

Çıkıs 5

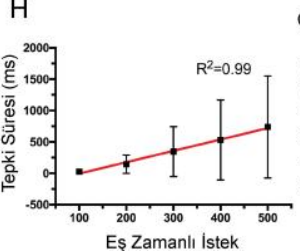

Çııı 6
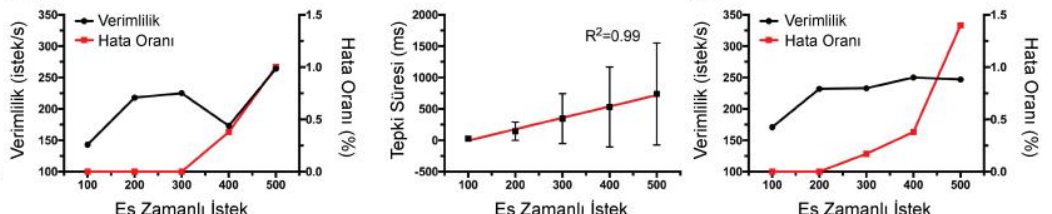

Şekil 5. Eş zamanlı veri girișinin sunucuda gerçekleşen farklı veri ișlem senaryolarına göre performans analizi. A) Çıkıș 1, B) Çıkış 2, C) Çıkış 3i, D) Çıııış 3ii, E) Çıkış 4i, F) Çıkış 4ii, G) Çıkış 5 ve H) Çıkıș 6 için ortaya çıkan tepki süresi, verimlilik ve hata oranları gösterilmiştir.

(Çıkış 3ii, Çıkış 4i ve Çıkış 4ii) ise eş zamanlı istek artıkça sunucuda oluşan ekstra e-posta gönderim yükünden dolayı yüksek tepki süresi ve hata oranı ile düșük verimlik gözlemlenmiș olup bildirim gönderim performansında ciddi bir düşüş görülmektedir.

Yüksek verimlilik ve düşük hata oranlarının istatistiksel olarak test edilmesi için bildirimin uygulama üstünden hasta ve doktora mesaj olarak gönderildiği durumda (Çılkış 6) farklı eş zamanlı istekler için 6 tekrarlı analiz yapılmıș ve sonuçlar ortalama değer \pm standart sapma değeri olarak Şekil 6'da gösterilmiştir. Şekil üzerindeki $*$, gruplar arasındaki istatistiksel farklılığı $(\mathrm{P}<0.05)$ göstermektedir. Şekil $6 \mathrm{~A}^{\prime} \mathrm{da}$ görüldüğü gibi 100 eş zamanlı istek için 150

istek/s verimliliğe ulaşırken 200 eş zamanlı istek için 200 istek/s verimliliğe ulaşılmıştır. İstek sayısı artıkça sunucu performansından dolayı verimlilikte istatistiksel olarak fark görülmemiș ve verimlilik 250 istek/s'nin altında kalmıştır. 100 eş zamanlı istek için verimlilik değeri diğer eş zamanlı istekler için olan verimlilik değerlerine göre istatistiksel olarak farklı olduğu bulunmuștur. Bununla beraber, Șekil 6B'de görüldüğü gibi eş zamanlı 100 ve 200 istek için hiç hata gözlemlenmezken, eș zamanlı 300 ve 400 istek için hata oranları sırasıyla \%0.1 ve $\% 0.25$ olarak ölçülmüştür. Bu eş zamanlı istekler için hata oranları arasında istatistiksel olarak fark görülmemiștir. 500 eş zamanlı istek için hata oranı \%1'e çlkarken, diğer isteklerin hata 
DEU FMD 22(64), 37-46, 2020

oranlarına göre istatistiksel fark görülmüștür. Böylece, 500 eş zamanlı istekte bile yüksek verimlik ( $>200$ istek/s) ve düşük hata oranı (<\%1.5) istatistiksel olarak gözlemlenmiștir.

\section{Tartıșma ve Sonuç}
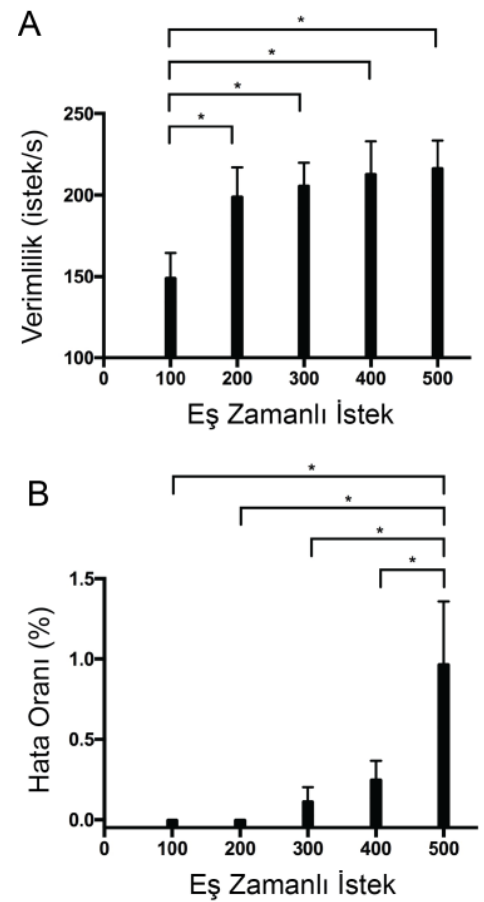

Şekil 6. Çıkış 6 için A) tepki süresi ve B) hata oranları.

posta bildirimi göndermenin uygun olmadığını ortaya koymaktadır. Bunun yanında bildirimlerin mesaj olarak uygulama üstünden gönderilmesi eş zamanlı isteklerde düşük hata oranları vermekte ve bu yöntemin çoklu kullanıcı için ölçeklenebilir olduğunu göstermektedir. Ancak sağlık verilerinin kayıpsız aktarılması için sunucu özellikleri iyileştirilebilir veya çoklu sunucu kullanılabilir [32]. Böylelikle verimlilik arttırılabileceği gibi tepki süresi de azaltılabilir. Bunun dışında uygulama bazında sunucudan verinin işlendiğine dair mesaj gelmezse veri tekrar gönderilebilir. Ancak bu yöntem için sunucuda aynı verinin tekrar ișlenmesini önlemek amacıyla önlem alınması gerekmekte, bu ise tepki süresinin artmasına sebep olabilmektedir [33].
Sonuçlardan da görüldüğü üzere eș zamanlı istek sayısı artıkça e-posta ile bildirim diğer veri işlem senaryolarına göre kötü performans vermekte, gönderilen verilerin $\% 25$ 'inden fazlası kayıp olmaktadır. $\mathrm{Bu}$ da kritik öneme sahip sağlık verilerinin işlenmesi sırasında e-

$\mathrm{Bu}$ çalışmada uzaktan kronik hasta izleminde kullanılabilecek yeni bir teletıp platformu sunulmuştur. Hastalar tansiyon aleti veya şeker ölçüm cihazından aldıkları sağlık verilerini platform üstünden kaydedebilir ve takiplerini yapan sağlık personeli ile paylaşabilirler. Sağlık personeli hasta sağlık verilerine anlık olarak ulaşabileceği gibi sağllk verilerindeki düzensizlikleri otomatik olarak saptamak için platform üstünden hastaya özel eşik değerleri belirleyebilir. Bu eșik değerinin așılması halinde, hastalara ve/veya sağlık personeline otomatik bilgilendirme mesajı veya e-posta gönderilerek, hastaya müdahale zaman kaybetmeksizin gerçekleştirilir. Böylelikle minimum iş yükü ile etkili bir kronik hasta takibi sağlanabilir. Platform eş zamanlı sağlık verisi girişi ile test edilmiş ve platform üstünden bilgilendirme mesajı gönderiminin yüksek verimlilik ve düşük hata oranıyla gerçekleştiği gözlenmiștir. Elde edilen sonuçlar tasarlanan platformun birçok kullanıcıdan gelecek veri akışını işleyebileceğini ve platformun ölçeklenebilir ve sürdürülebilir olduğunu göstermiştir. Sunulan teletıp platformunda veri girișinin manuel olarak yapılması bir kısıt olarak görülebilir. Kronik hastalıkların yaşla beraber arttığı da göz önüne alındığında, ileride sağlık verilerinin otomatik olarak cihazlar üstünden platforma aktarılması ile kullanıcı memnuniyeti artırılacak ve hatalı veri girișlerinin önüne geçilecektir [34]. Bununla beraber, yaşlı hastaların duyusal ve motor becerilerinde bozulmalar olabilmektedir. $\mathrm{Bu}$ bozulmalara karşı platformun görsellerinin ve bildirim uyarılarının uyarlanması ise platformun daha büyük bir hasta kitlesi tarafından kabul görmesini sağlayacaktır $[34,35]$. İleride platformun hastalar ve doktorlar tarafından test edilmesi ile kullanılabilirliğinin ölçülmesi planlanmaktadır. Ayrıca, hasta kullanım memnuniyetini ve kabulünü arttırmak amacıyla platforma, nesnelerin interneti teknolojisinden yararlanılarak, gerçek zamanlı ve otomatik veri aktaran giyilebilir medikal cihazların entegre edilmesi düşünülmektedir. 
DEU FMD 22(64), 37-46, 2020

Sunulan platform ihtiyaçlar doğrultusunda güncellenmeye ve geliştirilmeye elverişli bir platformdur. Örneğin, hastaların sağlık verilerindeki zamana bağlı eğilimlerin belirlenmesi ve birçok sağllk verisinin beraber değerlendirilip ilișkilendirilmesinin, hastalara ve sağlık personeline büyük fayda sağlayacağı düşünülmektedir. Şöyle ki; çocuklarda uzun süre devam eden yükselmiş kan basıncı değeri yetişkinlik evresinde hipertansiyon gelişimine yol açabilmektedir [36]. Ayrıca, diyabetik olmayan ama yükselmiş kan şekeri olan hastaların kalp ve böbrek hastalığına yakalanma riski artmaktadır [37]. Bununla beraber diyabet, hastaların kalp ritimlerinin bozulmasına ve hipertansiyon geliștirmelerine sebep olabilmektedir [38]. Diyabet hastalarının kan basınçlarının sıkı kontrol altına tutulması ölüm oranlarını azaltabilmektedir [39]. Bu sebeple, ileride, yeni bir fonksiyon olarak platforma, verilerdeki eğilimlere ve verilerin birbirleri ile ilişkisine bakılarak çeşitli uyarı mesajları oluşturulması opsiyonunun entegre edilmesi planlanmaktadır. Böylelikle platform üstünden farklı hastalık senaryolarını kapsayıcı uyarı mesajlarının gönderilmesi sağlanabilecektir.

\section{Teşekkür}

$\mathrm{Bu}$ çalışma İzmir Yüksek Teknoloji Enstitüsü (IYYTE) tarafından 2017IYTE61 numaralı proje kapsamında desteklenmiștir. Yazar yararlı önerileri için IYTE Biyomühendislik Bölümü'nden Doç. Dr. Engin Özçivici'ye ve Saniber Ltd. Şti.'den Başak Tekin'e teșekkürlerini sunar.

\section{Kaynakça}

[1] The World Health Organization Regional Office for Africa. 2017. http://www.afro.who.int/healthtopics/noncommunicable-diseases (Erişim tarihi: 17.01.2019).

[2] The World Health Organization. 2018. http://www.who.int/gho/ncd/mortality_morbidity /ncd total/en/ (Erișim tarihi: 17.01.2019).

[3] Rauniyar, M., Shrestha, J., Raj, L. B., Shrestha, A., Acharya, K. 2017. Disease Pattern, Morbidity Indicators in a Tertiary Care Center of a Developing Country, Annals of Public Health and Research, Cilt. 4, s. 1055.

[4] Bane, A., Bayisa, T., Adamu, F., Abdissa, S. G. 2016 Medical Admissions and Outcomes at Saint Paul's Hospital, Addis Ababa, Ethiopia: a retrospective study, Ethiopian Journal of Health Development, Cilt. 30, s. 50-56.

[5] Hernandez, C., Jansa, M., Vidal, M., Nunez, M., Bertran, M. J., Garcia-Aymerich, J., Roca, J. 2009. The burden of chronic disorders on hospital admissions prompts the need for new modalities of care: a cross-sectional analysis in a tertiary hospital, QJM, Cilt. 102, s. 193202. DOI: $10.1093 /$ qjmed/hcn172
[6] Bloom, D.E., Ca ero, E.T., Jané-Llopis, E., AbrahamsGessel, S., Bloom, L.R., Fathima, S., Feigl, A.B., Gaziano, T., Mowa , M., Pandya, A., Prettner, K., Rosenberg, L., Seligman, B., Stein, A.Z., Weinstein, C. 2011. The global economic burden of noncommunicable diseases, World Economic Forum, Geneva, 46s.

[7] Boutayeb, A. 2006. The double burden of communicable and non-communicable diseases in developing countries, Trans R Soc Trop Med Hyg, Cilt. 100 , s. 191-199. DOI: 10.1016/j.trstmh.2005.07.021

[8] The World Health Organization. 2018. http://www.who.int/en/news-room/factsheets/detail/noncommunicable-diseases (Erișim tarihi: 17.01.2019).

[9] Rietzschel, E. R., De Buyzere, M. L. 2018. Hypertension: time for doctors to switch the driver's seat?, Lancet, Cilt. 391, s. 914-916. DOI: 10.1016/S0140-6736(18)30317-9

[10] Kessel, K. A., Vogel, M. M., Kessel, C., Bier, H., Biedermann, T., Friess, H., Herschbach, $P_{\text {., von }}$ Eisenhart-Rothe, R., Meyer, B., Kiechle, M., Keller, U., Peschel, C., Schmid, R. M., Combs, S. E. 2017. Mobile Health in Oncology: A Patient Survey About AppAssisted Cancer Care, JMIR Mhealth Uhealth, Cilt. 5, s. e81. DOI: $10.2196 /$ mhealth.7689

[11] Strehle, E. M., Shabde, N. 2006. One hundred years of telemedicine: does this new technology have a place in paediatrics?, Arch Dis Child, Cilt. 91, s. 956-959. DOI: $10.1136 /$ adc. 2006.099622

[12] Sood, S., Mbarika, V., Jugoo, S., Dookhy, R., Doarn, C. R., Prakash, N., Merrell, R. C. 2007. What is telemedicine? A collection of 104 peer-reviewed perspectives and theoretical underpinnings, Telemed J E Health, Cilt. 13, s. 573-590. DOI: 10.1089/tmj.2006.0073

[13] Kucukoner, E. M., Yavuz, E. 2016. Yaşlı ve engelliler hastalar için uzaktan takip sistemi, Mühendislik Bilimleri ve Tasarım Dergisi, Cilt. 4, s. 99-104. DOI: 10.21923/jesd.17324.

[14] Isık, A. H., Guler, I. 2010. Teletıpta mobil uygulama çalışması ve mobil iletişim teknolojilerinin analizi, Bilişim Teknolojileri Dergisi, Cilt. 3, s. 1-10.

[15] Yılmaz, A., Guven, A. 2017. Kablosuz Hasta Takip Sistemi, Electronic Letters on Science and Engineering, Cilt. 13, s. 16-30.

[16] Piette, J. D., Valverde, H., Marinec, N., Jantz, R., Kamis, K., de la Vega, C. L., Woolley, T., Pinto, B. 2014. Establishing an independent mobile health program for chronic disease self-management support in bolivia, Front Public Health, Cilt. 2, s. 95. DOI: 10.3389/fpubh.2014.00095

[17] Azar, M., Gabbay, R. 2009. Web-based management of diabetes through glucose uploads: Has the time come for telemedicine?, Diabetes Research and Clinical Practice, Cilt. 83, s. 9-17. DOI: 10.1016/j.diabres.2008.09.055

[18] Avci, Y. D., Gozum, S. 2018. Kırsal Alanda Yaşayan Yaşlılar için Sağlık Hizmeti Sunum Modelleri ve TeleSağlık, TTJFMPC, Cilt. 12, s. 56-67. DOI: $10.21763 /$ tjfmpc.400067

[19] Ekici, S. K., Gumus, O. 2016. Yaşlılıkta teknolojinin kullanımı, Ege Tıp Dergisi, Cilt. 55, s. 26-30. DOI: 10.19161/etd.344199 


\section{DEU FMD 22(64), 37-46, 2020}

[20] Agarwal, R., Bills, J. E., Hecht, T. J., Light, R. P. 2011. Role of home blood pressure monitoring in overcoming therapeutic inertia and improving hypertension control: a systematic review and metaanalysis, Hypertension, Cilt. 57, s. 29-38. DOI: 10.1161/HYPERTENSIONAHA.110.160911

[21] McManus, R. J., vd. 2018. Efficacy of self-monitored blood pressure, with or without telemonitoring, for titration of antihypertensive medication (TASMINH4): an unmasked randomised controlled trial, Lancet, Cilt. 391, s. 949-959. DOI: 10.1016/S0140-6736(18)30309-X

[22] Friedman, R. H., Kazis, L. E., Jette, A., Smith, M. B., Stollerman, J., Torgerson, J., Carey, K. 1996. A telecommunications system for monitoring and counseling patients with hypertension. Impact on medication adherence and blood pressure control Am J Hypertens, Cilt. 9, s. 285-292. DOI: 10.1016/0895-7061(95)00353-3

[23] Piette, J. D., Datwani, H., Gaudioso, S., Foster, S. M., Westphal, J., Perry, W., Rodríguez-Saldaña, J., Mendoza-Avelares, M. O., Marinec, N. 2012. Hypertension Management Using Mobile Technology and Home Blood Pressure Monitoring: Results of a Randomized Trial in Two Low/MiddleIncome Countries, Telemedicine and e-Health, Cilt. 18, s. 613-620. DOI: 10.1089/tmj.2011.0271

[24] Ferrante, D., Varini, S., Macchia, A., Soifer, S., Badra, R., Nul, D., Grancelli, H., Doval, H., Investigators, G. 2010. Long-term results after a telephone intervention in chronic heart failure: DIAL (Randomized Trial of Phone Intervention in Chronic Heart Failure) follow-up, J Am Coll Cardiol, Cilt. 56, s. 372-378. DOI: 10.1016/j.jacc.2010.03.049

[25] Bellazzi, R., vd. 2002. A telemedicine support for diabetes management: the T-IDDM project, Comput Methods Programs Biomed, Cilt. 69, s. 147-161. DOI: 10.1016/S0169-2607(02)00038-X

[26] Milani, R. V., Lavie, C. J., Bober, R. M., Milani, A. R. Ventura, H. O. 2017. Improving Hypertension Control and Patient Engagement Using Digital Tools, Am J Med, Cilt. 130, s. 14-20. DOI: 10.1016/j.amjmed.2016.07.029

[27] Shoulders, B., Powell, L. 2019. Reaching for Goal: Incorporating the Latest Hypertension Guidelines Into Practice, The Journal for Nurse Practitioners, Cilt. 15, s. 102-109. DOI: 10.1016/j.nurpra.2018.09.011

[28] Milani, R. V., Bober, R. M., Milani, A. R. 2017. Hypertension management in the digital era, Curr Opin Cardiol, Cilt. 32, s. 373-380. DOI: 10.1097/HCO.0000000000000405

[29] Bode, B. W. 2000. Clinical utility of the continuous glucose monitoring system, Diabetes Technol Ther Cilt. 2, s. 35-41. DOI: 10.1089/15209150050214104

[30] Ndlovu, K., Littman-Quinn, R., Park, E., Dikai, Z., Kovarik, C. L. 2014. Scaling up a Mobile Telemedicine Solution in Botswana: Keys to Sustainability, Front Public Health, Cilt. 2, s. 275. DOI: 10.3389/fpubh.2014.00275

[31] Fromme, H. B., Chen, C. O., Fine, B. R., Gosdin, C., Shaughnessy, E. E. 2018. Pediatric Hospitalist Workload and Sustainability in University-Based Programs: Results from a National Interview-Based
Survey, J Hosp Med, Cilt. 13, s. 702-705. DOI: 10.12788/jhm.2977

[32] Trent, S., Tatsubori, M., Suzumura, T., Tozawa, A., Onodera, T. 2008. Performance Comparison of PHP and JSP as Server-Side Scripting Languages, s. 164182. Issarny, V., Schantz, R., ed. 2008. Middleware 2008, Springer, Berlin, Heidelberg, 428s. DOI: 10.1007/978-3-540-89856-6_9

[33] Hu, X., Wang, L., Sheng, Z., TalebiFard, P., Zhou, L., Liu, J., Leung, V. C. M. 2014. Towards a service centric contextualized vehicular cloud. The fourth ACM international symposium on development and analysis of intelligent vehicular networks and applications, 21-26 Eylül, Montreal, Kanada, s. 73-80. DOI: $10.1145 / 2656346.2656351$

[34] Bujnowska-Fedak, M. M., Grata-Borkowska, U. 2015. Use of telemedicine-based care for the aging and elderly: promises and pitfalls, Smart Homecare Technology and TeleHealth, Cilt. 2015, s. 91-105. DOI: $10.2147 /$ SHTT.S59498.

[35] Hanson, J., Percival, J., Aldred, H., Brownsell, S., Hawley, M. 2007. Attitudes to telecare among older people, professional care workers and informal carers: a preventative strategy or crisis management?, Universal Access in the Information Society, Cilt. 6, s. 193-205. DOI: 10.1007/s10209007-0075-y

[36] Bao, W., Threefoot, S. A., Srinivasan, S. R., Berenson, G. S. 1995. Essential hypertension predicted by tracking of elevated blood pressure from childhood to adulthood: the Bogalusa Heart Study, Am J Hypertens, Cilt. 8, s. 657-665. DOI: 10.1016/08957061(95)00116-7

[37] Ali, M. K., Bullard, K. M., Saydah, S., Imperatore, G., Gregg, E. W. 2018. Cardiovascular and renal burdens of prediabetes in the USA: analysis of data from serial cross-sectional surveys, 1988-2014, Lancet Diabetes Endocrinol, Cilt. 6, s. 392-403. DOI: 10.1016/S22138587(18)30027-5.

[38] Su, W., Guo, Z., Randall, D. C., Cassis, L., Brown, D. R., Gong, M. C. 2008. Hypertension and disrupted blood pressure circadian rhythm in type 2 diabetic $\mathrm{db} / \mathrm{db}$ mice, Am J Physiol Heart Circ Physiol, Cilt. 295, s. H1634-1641. DOI: 10.1152/ajpheart.00257.2008

[39] Heart Outcomes Prevention Evaluation (HOPE) Study Investigators. 2000. Effects of ramipril on cardiovascular and microvascular outcomes in people with diabetes mellitus: results of the HOPE study and MICRO-HOPE substudy. Heart Outcomes Prevention Evaluation Study Investigators, Lancet, Cilt. 355 , s. 253-259. DOI: $10.1016 /$ S01406736(99)12323-7 